\title{
Validity and Reliability of Korean Version of the Auditory Behavior in Everyday Life Questionnaire
}

\author{
Jaehee Choi', Keonseok Yoon ${ }^{1}$, Hyunsook Jang ${ }^{2}$ \\ 'Department of Speech Pathology and Audiology, Graduate School, Hallym University, Chuncheon, Korea \\ ${ }^{2}$ Division of Speech Pathology and Audiology, Research Institute of Audiology and Speech Pathology, College of Natural Sciences, \\ Hallym University, Chuncheon, Korea
}

한국어 버전 일상생활 청각행동 설문지의 신뢰도와 타당도

최재희 ${ }^{1} \cdot$ 윤건석 ${ }^{1} \cdot$ 장현숙 $^{2}$

한림대학교 일반대학원 언어병리청각학과', 한림대학교 자연과학대학 언어청각학부· 청각언어연구소 ${ }^{2}$

\begin{abstract}
Purpose: The Auditory Behavior in Everyday Life (ABEL) questionnaire has been proven for its reliability and validity across various cultures for assessing auditory behaviors of children with hearing loss. The study's purpose was to translate the ABEL questionnaire into Korean and verify reliability and validity of Korean version of ABEL (ABEL-K). Methods: After translation, the ABEL-K evaluated for appropriateness, and back translated by a bilingual user to compare to the original regarding semantic equivalence. ABEL-K was completed by 48 parents of children (from ages 3-15 years) with hearing loss (9 children with hearing aids and 39 children with cochlear implants). Among the 48 children, 11 were in preschool, 16 in elementary, and 21 in secondary. Internal consistency reliability of ABEL-K was verified by Chronbach's alpha. The mixed factorial ANOVA was conducted to compare the age group and the evaluation areas (aural-oral, auditory awareness, and social/conversational skills). The Pearson Correlation Coefficient between the scores and chronological age, and scores and period of $\mathrm{Cl}$ experience were evaluated, respectively. Results: The results indicated that although ABEL-K showed good internal consistency reliability $(\alpha=0.90)$, there seems to be issues in its validity due to ambiguous expression and the cultural differences. The ABEL scores among age groups were not significantly different. However, there was a significant difference in ABEL scores between auditory awareness and social/conversational skill areas. There was significant correlation with $\mathrm{Cl}$ experience, but not with chronological age. Conclusion: Thus, this study suggests a way that ABEL-K should be utilized, taking precautions in the interpretation of the results.
\end{abstract}

Key Words: Auditory Behavior in Everyday Life, Questionnaire, Children with hearing loss, Reliability.

Received: September 30, 2016 / Revised: October 15, 2016 / Accepted: October 26, 2016

Correspondence: Hyunsook Jang, Division of Speech Pathology and Audiology, College of Natural Sciences, Hallym University, 1 Hallimdaehak-gil, Chuncheon 24252, Korea

Tel: +82-33-248-2218 / Fax: +82-33-256-3420 / E-mail: hsjang@hallym.ac.kr

\section{INTRODUCTION}

청능재활이란 청각장애인이 장애로 인해 일상 속 의사소통 에 지장을 받는 정도를 평가하고, 중재하고, 관리함으로써 듣기 영역이 제대로 기능하지 못하여 발생하는 제한을 최소화하는 과정이다(ASHA, 2001). 그러므로 의사소통에 지장이 있는 정 도 및 제한을 올바르게 평가하는 것이 청능재활의 시작이며, 이 를 바탕으로 보청기 및 인공와우를 처방하게 되므로 가장 중요 한 과정이라 할 수 있다. 특히 청각장애 아동의 경우에는 청각
및 언어 발달 지체의 위험이 따르기 때문에 청각장애의 조속한 발견 및 평가의 중요성이 더욱 강조된다. 이를 위해 임상 현장에 서 행동청능평가, 전기음향학적 및 전기생리학적 평가 등과 더 불어 다양한 설문지 및 체크리스트 등이 적극 활용되고 있다. 청각장애 아동 대상의 설문지는 아동 청각발달의 정도에 따라 특정한 청각행동을 주변의 보호자가 관찰할 수 있으리란 것을 전제하며, 오랜 기간 아동을 관찰해 온 보호자의 관점을 통해 아동의 청각행동을 손쉽게 평가할 수 있다는 장점이 있다.

특히 부모용 설문지는 더욱 지속적인 관찰의 결과를 반영할 
수 있다는 장점으로 인해 교사용이나 아동용 설문지보다 많이 개발되었으며, 일상생활 청각행동(Auditory Behavior in Everyday Life, ABEL) (Purdy et al., 2002) 설문지는 부모용 설 문지 중 하나로서 신뢰도 및 타당도, 시행용이성 등에서 우수한 설문지로 평가받고 있다(Choi et al., 2015). ABEL은 4 14세 아 동을 대상으로 7점 척도를 사용하여 일상생활 속 아동의 청각 행동들을 평가하며, 장애아동이 청각-구화를 사용하는 정도 를 평가하는 청각-구화(aural-oral) 영역, 청각적 탐지 및 이해 정도를 평가하는 청각적 인식(auditory awareness) 영역, 사회 적 기술 및 대화기술을 사용하는 정도를 평가하는 사회적/대 화 기술(social/conversational skills) 영역을 총 24문항으로 평 가한다(Purdy et al., 2002).

청각장애 아동을 대상으로 하는 설문지 중 대부분이 청각구화 및 청각적 인식 영역에 초점을 두는 반면, ABEL은 이들 영역을 포함하는 동시에 아동의 청각경험에 따른 심리사회적 결과까지 평가한다는 점에서 타 설문지들과 구분지을 수 있다. Anderson \& Matkin(1991)은 청각장애의 정도에 따라 아동이 경험하는 심리사회적 결과가 다양하게 나타나는 등 청각장애가 아동의 사회성에 미치는 영향이 지대함을 보고하였으며, 다른 많은 연구들에서도 청각장애 아동이 경험하는 사회적 어려움 을 완화해야 할 필요성을 보고하였다(Gfeller \& Schum, 1994; Paul \& Jackson, 1993; Schloss \& Smith, 1990; Schum, 1991).

ABEL은 현재까지 영어 외에 브라질어(Souza et al., 2011), 히브리어와 아랍어(Geal-Dor et al., 2014), 스페인어(Herrera et al., 2015), 페르시아어(Zanjani et al., 2015) 등의 언어로 번역되 어 사용 중에 있으며, $\mathrm{ABEL}$ 의 신뢰도와 타당도와 관련된 연 구들(Geal-Dor et al., 2014; Herrera et al., 2015; Purdy et al., 2002; Souza \& Iorio, 2014; Souza et al., 2011; Zanjani et al., 2016)은 우수한 신뢰도와 타당도를 보고하였다. Purdy et al.(2002)은 인공와우를 착용한 7명의 아동(3 12세)을 대상으 로 수행한 연구에서 수술 전후로 $\mathrm{ABEL}$ 검사를 6 번 시행한 결 과, 아동의 말지각 점수와 $\mathrm{ABEL}$ 점수가 시간에 따라 유의미 한 향상을 보였으며, ABEL의 신뢰도는 크론바흐 알파(Cronbach's $\alpha$ )값 0.95로 우수함을 보고하였다. Herrera et al.(2015) 은 청각장애 아동의 부모 100 명을 대상으로 $\mathrm{ABEL}$ 검사를 실 시하여 검사-재검사 신뢰도가 0.86 , 내적일치도가 0.73 으로 나 타남을 보고하였다. Zanjani et al.(2016)은 보청기와 인공와우 를 착용한 아동(4 6세)의 부모 43명을 대상으로 ABEL 검사 를 2회 실시한 결과, 검사-재검사 간 결과에서 세 가지 평가영 역 사이에 유의한 상관관계가 있었으며 전체 크론바흐 알파값 이 0.82로 나타났음을 보고하였다. Souza \& Iorio(2014)가 수행 한 연구에서는 18 명의 아동(4 13세)을 대상으로 브라질어 버 전 $\mathrm{ABEL}$ 의 검사-재검사 신뢰도와 내적일치도를 확인한 결과,
검사-재검사 결과에 유의미한 차이가 없었으며, 크론바흐 알파 값이 0.7 이상인 것으로 나타났다. 또한 아동의 청력손실 정도 가 청각적 인식 평가영역과 상관관계가 있으며, 특정 문항 ‘필요 할 때 도움을 요청한다(Asks for help in situations where it is needed).'가 부모의 교육수준과 상관관계가 있음을 보고하였 다. Souza et al.(2011)은 청각장애 아동(4 13세)의 보호자 31명 을 대상으로 브라질어 버전 $\mathrm{ABEL}$ 검사를 실시한 결과, 아동의 청력손실 정도와 청각-구화 평가영역 점수 간 유의미한 관계가 있음을 보고하였으며, 추가로 하루 중 보청기 착용시간이 더 긴 아동일수록 $\mathrm{ABEL}$ 점수가 더 높게 나타났음을 보고하였다. Geal-Dor et al.(2014)은 인공와우를 이식한 아동(3 14세)의 부모 61명을 대상으로 $\mathrm{ABEL}$ 검사를 실시한 결과, 인공와우 이 식연령과 설문지 점수 간에 유의미한 관계가 있음을 보고하였 다. Choi et al.(2015)은 ABEL 설문지를 적용한 논문들을 체계 적으로 분석한 결과, $\mathrm{ABEL}$ 이 검사-재검사 신뢰도, 타당도, 규 준화, 시행용이성 등에 대해 임상적 근거를 갖추고 있는 것으로 평가하였다.

$\mathrm{ABEL}$ 의 검증된 신뢰도와 타당도 그리고 국제적인 사용 현 황을 고려할 때, $\mathrm{ABEL}$ 설문지를 국내 청각장애 아동에게 사 용하는 것이 적절한지 확인할 필요가 있다. 그러므로 본 연구 의 목적은 한국어 버전 $\mathrm{ABEL}$ 설문지를 실제 임상에 적용하여 그 신뢰도와 타당도를 검증하는 것이며, 이를 위해 $\mathrm{ABEL}$ 점수 가 청각장애 아동의 생활연령 또는 인공와우 착용기간에 따른 차이를 보이는지 여부를 국내 학제상의 구분에 따라 유아, 초 등, 중등 연령대로 나누어 확인하였다.

\section{MATERIALS AND METHODS}

\section{연구 대상}

본 연구는 생명윤리 심의기관의 승인(HIRB-2015-097) 하에 청각장애 아동 어머니 48명을 모집하여 한국어 버전 $\mathrm{ABEL}$ 설 문지 조사를 실시하였다. 연구 대상자는 청각장애 아동 48명(남 성 22명, 여성 26명)으로 유아 11명, 초등 16명, 중등 21명이었으 며, 전체 연구 대상자의 평균 연령은 10.73세(3;5 15;83)였다. 연 구대상자가 사용하는 보장구는 보청기 9명, 인공와우(cochlear implant, CI) 39명이었으며, 평균 착용기간은 7.94년(0;3 14;42) 이었다. 본 연구의 대상 아동에 대한 전반적인 정보를 Table 1 에 제시하였다.

\section{설문지 분석}

본 연구에서는 Purdy et al.(2002)이 개발한 ABEL 설문지 원본을 번역하였으며, 이때 원문의 의도를 최대한 반영하는 데 초점을 두었다. 한국어 버전 $\mathrm{ABEL}$ 번역의 적절성을 평가하기 
Table 1. Descriptive characteristics of subjects

\begin{tabular}{|c|c|c|c|c|c|}
\hline Age group & Subjects & Gender & $\mathrm{CA}(\mathrm{mo})$ & Period of HA \& CI experience (mo) & Device use $(\mathrm{L}+\mathrm{R})$ \\
\hline \multirow{11}{*}{ Preschool $(\mathrm{n}=11)$} & S1 & $\mathrm{F}$ & 42 & 14 & $\mathrm{CI}+\mathrm{CI}$ \\
\hline & S2 & M & 51 & 22 & $\mathrm{CI}+\mathrm{CI}$ \\
\hline & S3 & M & 51 & 34 & $\mathrm{CI}+\mathrm{CI}$ \\
\hline & S4 & M & 51 & 49 & $\mathrm{CI}+\mathrm{HA}$ \\
\hline & S5 & M & 51 & 16 & $\mathrm{CI}+\mathrm{CI}$ \\
\hline & S6 & M & 52 & 33 & $\mathrm{EAS}+\mathrm{HA}$ \\
\hline & S7 & M & 53 & 27 & $\mathrm{CI}+\mathrm{CI}$ \\
\hline & S8 & M & 57 & 10 & $\mathrm{CI}+\mathrm{CI}$ \\
\hline & S9 & $\mathrm{F}$ & 61 & 48 & $\mathrm{CI}+\mathrm{CI}$ \\
\hline & S10 & M & 64 & 54 & $\mathrm{HA}+\mathrm{HA}$ \\
\hline & S11 & $\mathrm{F}$ & 74 & 31 & $\mathrm{CI}(\mathrm{R})$ \\
\hline \multirow{16}{*}{ Elementary $(n=16)$} & S12 & $\mathrm{M}$ & 80 & 73 & $\mathrm{CI}(\mathrm{L})$ \\
\hline & S13 & $\mathrm{F}$ & 83 & 66 & $\mathrm{CI}+\mathrm{CI}$ \\
\hline & S14 & $\mathrm{F}$ & 84 & 68 & $\mathrm{CI}+\mathrm{CI}$ \\
\hline & S15 & M & 92 & 74 & $\mathrm{CI}+\mathrm{CI}$ \\
\hline & S16 & M & 98 & 3 & $\mathrm{HA}+\mathrm{CI}$ \\
\hline & S17 & $\mathrm{F}$ & 100 & 28 & $\mathrm{HA}+\mathrm{HA}$ \\
\hline & S18 & $\mathrm{F}$ & 114 & 99 & $\mathrm{CI}+\mathrm{CI}$ \\
\hline & S19 & M & 120 & 84 & $\mathrm{HA}+\mathrm{CI}$ \\
\hline & S20 & M & 129 & 101 & $\mathrm{CI}(\mathrm{R})$ \\
\hline & S21 & M & 137 & 107 & $\mathrm{CI}+\mathrm{HA}$ \\
\hline & S22 & M & 138 & 125 & $\mathrm{CI}+\mathrm{CI}$ \\
\hline & S23 & $\mathrm{F}$ & 139 & 80 & $\mathrm{HA}+\mathrm{HA}$ \\
\hline & S24 & $\mathrm{F}$ & 143 & 116 & $\mathrm{CI}+\mathrm{CI}$ \\
\hline & S25 & $\mathrm{F}$ & 143 & 120 & $\mathrm{CI}+\mathrm{CI}$ \\
\hline & S26 & M & 147 & 110 & $\mathrm{HA}+\mathrm{CI}$ \\
\hline & S27 & M & 147 & 132 & $\mathrm{HA}(\mathrm{R})$ \\
\hline \multirow{21}{*}{ Secondary $(n=21)$} & S28 & $\mathrm{F}$ & 150 & 130 & $\mathrm{HA}+\mathrm{HA}$ \\
\hline & S29 & $\mathrm{F}$ & 151 & 134 & $\mathrm{CI}+\mathrm{CI}$ \\
\hline & S30 & $\mathrm{F}$ & 155 & 126 & $\mathrm{EAS}+\mathrm{HA}$ \\
\hline & S31 & M & 162 & 156 & $\mathrm{CI}+\mathrm{CI}$ \\
\hline & S32 & $\mathrm{F}$ & 164 & 120 & $\mathrm{CL}+\mathrm{HA}$ \\
\hline & S33 & M & 169 & 146 & $\mathrm{CI}(\mathrm{R})$ \\
\hline & S34 & $\mathrm{F}$ & 170 & 146 & $\mathrm{CI}+\mathrm{CI}$ \\
\hline & S35 & $\mathrm{F}$ & 172 & 52 & $\mathrm{HA}+\mathrm{HA}$ \\
\hline & S36 & $\mathrm{F}$ & 174 & 154 & $\mathrm{CI}+\mathrm{CI}$ \\
\hline & S37 & M & 174 & 170 & $\mathrm{HA}+\mathrm{HA}$ \\
\hline & S38 & $\mathrm{F}$ & 174 & 147 & $\mathrm{CI}+\mathrm{CI}$ \\
\hline & S39 & $\mathrm{F}$ & 177 & 90 & $\mathrm{CI}+\mathrm{CI}$ \\
\hline & S40 & $\mathrm{F}$ & 178 & 162 & $\mathrm{CI}+\mathrm{CI}$ \\
\hline & S41 & $\mathrm{F}$ & 178 & 91 & $\mathrm{HA}+\mathrm{HA}$ \\
\hline & S42 & $\mathrm{F}$ & 182 & 168 & $\mathrm{CI}+\mathrm{CI}$ \\
\hline & S43 & $\mathrm{F}$ & 185 & 164 & $\mathrm{CI}+\mathrm{CI}$ \\
\hline & S44 & M & 187 & 24 & $\mathrm{HA}+\mathrm{HA}$ \\
\hline & S45 & $\mathrm{F}$ & 188 & 156 & $\mathrm{CI}+\mathrm{CI}$ \\
\hline & S46 & M & 189 & 169 & $\mathrm{CI}+\mathrm{CI}$ \\
\hline & S47 & $\mathrm{F}$ & 189 & 169 & $\mathrm{HA}+\mathrm{CI}$ \\
\hline & S48 & $\mathrm{F}$ & 190 & 173 & CI (R) \\
\hline
\end{tabular}

CI: cochlear implant, HA: hearing aid, EAS: Electro-Acoustic Stimulation 
위해 청각학과 석사 이상의 학위를 소지한 청능사 3 명과 청각 장애 아동의 부모 3명에게 의뢰하여 1) '아주 적절함', 2) '적절 함', 3) ‘보통', 4) ‘부적절함', 5) ‘아주 부적절함' 중 하나를 고르는 5 점 척도의 문항적절성 평가를 1 차로 실시하였다. 평균 3 점 이 하의 점수를 받은 문항은 새로 번역하여 청각학과 석사 및 박 사 학위를 소지한 자로서 앞서 의뢰한 3명을 제외한 14 명을 대 상으로 2차 문항적절성 평가를 실시하였다. 그 결과, 한국어 버 전 $\mathrm{ABEL}$ 번역의 적절성 점수는 평균 4.46점(3.71 4.79)으로 나 타났다. 마지막으로 청각학 박사 과정에 재학하고 있는 이중언 어 사용자(영어-한국어)에게 의뢰하여 한국어 버전 ABEL을 영 어로 역번역한 후, 원문의 의미와 동일한지를 확인하였다. 다만, 문항 16(Will whisper a personal message)과 문항 22(Sings)의 경우에는 적절성 평가과정에서 문항의 의미를 보다 명료화해야 할 필요가 수차례 제기되었으므로 원문의 의도를 고려하여 적 극적으로 의역하였다. 최종적으로 결정된 한국어 버전 $\mathrm{ABEL}$ 은 청각-구화 영역 11 문항 $(1,2,3,4,10,12,13,14,18,21,22)$, 청각적 인식 영역 10 문항 $(7,8,15,16,18,19,20,22,23,24)$, 사 회적/대화 기술 영역 5 문항 $(5,6,9,11,17)$ 으로 총 24 문항이며, 이 중 문항 18 과 22 번은 청각-구화 영역과 청각적 인식 영역 양쪽에 포함되어 있다(Table 2).

\section{연구 절차}

본 연구에서 청각장애 아동의 부모를 모집하기 위해 각 지역 의 청각센터 및 언어치료실에 안내문을 배포하여 총 48명을 모 집하였다. 참여희망자들은 설문지 및 연구절차에 대한 안내를 받은 후 동의서를 작성하였으며, 사전 설문지에서 청각장애 아 동에 대한 기본적인 인적사항과 착용한 보장구의 종류와 제조 사, 제품명, 보장구 착용기간, 중복장애 여부 등에 대해 응답한 후 설문지 검사를 진행하였다. 설문지에 응답할 때는 각 문항 마다 '전혀 아니다'(0), '거의 아니다'(1), '가끔'(2), '때때로'(3), '자 주 그렇다'(4), '거의 그렇다'(5), '항상'(6) 중 하나를 선택하도록 하였다. 연구 대상자가 설문지에 응답하는 도중에 의문이 있을 경우 적절히 안내하였으며, 설문지 응답이 끝난 후에는 설문지 에서 누락된 문항이 있는지 확인하고 회수하였다. 설문지 점수 는 각 문항별로 0 6점으로, 각 문항의 점수들을 합산하여 영역 별 또는 총 24문항 전체 평균점수로 산정하여 코딩하였다. 단, 문항 11번과 문항 20번이 부정적 내용을 취하였으므로 점수 계 산에서 전체적으로 높은 점수가 긍정적인 특성/태도/행동을 나타내기 위하여 두 문항의 경우 보정한 점수를 부여하였다.

\section{통계 분석}

통계적 분석은 IBM SPSS version 23 (IBM Corp., Armonk, $\mathrm{NY}, \mathrm{USA}$ )을 사용하였다. $\mathrm{ABEL}$ 점수의 전체 및 각 영역별 평
균과 표준편차 등의 기술통계를 구하였고, 신뢰도 분석을 위해 크론바흐 알파값으로 내적일관성을 검증하였다. 연령대 그룹 (유아, 초등, 중등)과 세 가지 평가영역(청각-구화, 청각적 인식, 사회적/대화 기술)의 $\mathrm{ABEL}$ 평균 점수를 비교하기 위해 혼합요 인 분산분석(mixed repeated measures ANOVA)과 사후분석 (Bonferroni)을 실시하였다. 또한 각 평가영역별 연령대 간 비 교를 위하여 독립표본 일원분산분석을, 연령대별 평가영역 간 비교를 위해 반복측정 일원분산분석을 각각 실시하였으며, 각 문항별로 연령대 그룹 간 차이를 비교하기 위하여 독립표본 일 원분산분석과 사후분석을 실시하였다. 아동의 생활연령 및 $\mathrm{CI}$ 착용기간과의 상관성을 분석하기 위해 상관계수(Pearson correlation coefficient)를 구하였다. CI 착용기간과의 상관성을 분 석할 때에는 총 48 명의 아동 중 39 명의 CI 착용 아동만을 대상 으로 하였다. 본 연구에서 실시한 통계분석은 모두 0.05 유의수 준에서 실시하였다.

\section{RESULTS}

\section{$\mathrm{ABEL}$ 문항의 신뢰도 분석}

본 연구에서는 한국어 버전 $\mathrm{ABEL}$ 의 신뢰도를 검증하기 위 해 세 가지 평가영역별로 크론바흐 알파(Cronbach's $\alpha$ ) 값을 구 하였으며, 이때 요인 분류는 원저자의 분류를 따랐다(Purdy et al., 2002). 그 결과, 청각-구화 요인(문항 $1,2,3,4,10,12,13$, $14,18,21,22)$ 의 알파값은 0.82 , 청각적 인식 요인(문항 $7,8,15$, $16,18,19,20,22,23,24)$ 의 알파값은 0.76 , 사회적/대화 기술 요인(문항 $5,6,9,11,17$ )의 알파값은 0.61 인 것으로 나타났으며, 전체 크론바흐 알파값은 0.90 이었다.

\section{$\mathrm{ABEL}$ 의 영역별 및 문항별 점수}

한국어로 번역된 $\mathrm{ABEL}$ 문항과 문항별 평균 점수, 그리고 연 령대별로 평균 점수 간에 유의한 차이가 있는지 분석한 결과를 Table 2에 제시하였다. 청각-구화 영역의 전체 평균 점수 범위 는 3.42 4.98이었으며, 유아 2.91 5.09, 초등 3.50 5.50, 중등 3.48 5.38이었다. 청각적 인식 영역의 전체 평균 점수 범위는 3.00 5.33이었으며, 유아는 2.36 5.36으로, 2점대였던 문항은 $7,16,24$ 였다. 초등은 2.81 5.50으로 24번 문항을 제외한 모든 문항이 3점대 이상이었으며, 중등은 3.38 5.52였다. 사회적/대 화 기술 영역의 전체 평균 점수 범위는 2.44 4.62로, 유아 2.45 4.73 , 초등 2.31 5.00, 중등 2.52 5.05였으며, 문항 5(낮선 사람 에게 먼저 말을 건다)만 모든 연령대에서 평균 2.31 2.52로 가 장 낮은 점수를 보였으며, 나머지 문항 4개는 모두 4점대의 점 수를 보였다. 각 문항에서 연령대별로 평균 점수 간에 유의한 차이가 있었던 것은 문항 $6,7,14,16,17$ 이었으며 사후분석 결 
Table 2. Korean version of questionnaire ABEL and statistical analysis on items of each evaluation area of ABEL for the age groups

\begin{tabular}{|c|c|c|c|c|c|c|}
\hline Evaluation area & Items & $\begin{array}{l}\text { Total } \\
\text { mean } \\
\text { score }\end{array}$ & Preschool & Elementary & Secondary & F value \\
\hline \multirow{9}{*}{ (1) Aural-orall } & 1 친숙한 사람에게 먼저 말을 건다. & 4.35 & 4.09 & 4.63 & 4.29 & 0.60 \\
\hline & 2 주의를 끌기 위해 상대방의 이름을 부른다. & 3.58 & 3.09 & 4.06 & 3.48 & 1.11 \\
\hline & $\begin{array}{l}3 \text { 시키지 않아도 “부탁해요” 또는 “고마워요” } \\
\text { 라고 말한다. }\end{array}$ & 3.75 & 2.91 & 3.94 & 4.05 & 2.59 \\
\hline & 4 친숙한 사람이 반겨주면 소리내어 답한다. & 4.98 & 4.55 & 5.06 & 5.14 & 0.93 \\
\hline & 10 필요하면 (구두로) 도움을 요청한다. & 4.94 & 5.09 & 5.00 & 4.81 & 0.27 \\
\hline & 12 주변에서 들리는 대화에 관심을 보인다. & 3.79 & 3.27 & 4.00 & 3.90 & 1.08 \\
\hline & 13 낯선 사람(들)이 반겨주면 소리내어 답한다. & 3.42 & 3.00 & 3.50 & 3.57 & 0.39 \\
\hline & 14 형제자매, 가족, 친구의 이름을 말한다. & 4.98 & 3.45 & 5.50 & 5.38 & $16.40^{\dagger}$ \\
\hline & 21 보호자 없이 또래들과 잘 어울려 논다. & 4.50 & 4.55 & 4.62 & 4.38 & 0.13 \\
\hline \multirow{8}{*}{ (2) Auditory awareness } & 7 전화 받을 때 적절하게 응답한다. & 3.90 & 2.45 & 4.06 & 4.52 & $7.68^{\dagger}$ \\
\hline & 8 방안에서 이름을 부르면 대답한다. & 4.92 & 4.91 & 4.94 & 4.90 & 0.00 \\
\hline & 15 초인종이나 문 두드리는 소리에 반응한다. & 5.00 & 5.09 & 5.13 & 4.86 & 0.29 \\
\hline & $\begin{array}{l}16 \text { 남에게 밝히고 싶지 않은 내용을 이야기할 때 } \\
\text { 속삭이며 말한다. }\end{array}$ & 3.63 & 2.36 & 3.94 & 4.05 & $3.60^{*}$ \\
\hline & $\begin{array}{l}19 \text { 큰 소리가 나면 알아챈다. } \\
\text { (예: 문 쾅 닫는 소리, 발 굴리는 소리) }\end{array}$ & 5.06 & 5.27 & 5.37 & 4.71 & 1.32 \\
\hline & 20 전화벨 소리에 반응하지 않는다. & 4.38 & 5.36 & 4.31 & 3.90 & 1.98 \\
\hline & 23 보장구가 작동하지 않으면 알아챈다. & 5.33 & 4.73 & 5.50 & 5.52 & 2.30 \\
\hline & 24 새롭게 발견한 소리를 실험해 본다. & 3.00 & 2.55 & 2.81 & 3.38 & 1.05 \\
\hline \multirow{2}{*}{$\begin{array}{l}\text { (1) Aural-oral }+ \\
\text { (2) Auditory awareness }\end{array}$} & $\begin{array}{l}18 \text { 주변에서 들리는 소리에 대해 질문한다. } \\
\text { (예: 비행기, 트럭, 동물) }\end{array}$ & 4.08 & 3.64 & 4.50 & 4.00 & 1.08 \\
\hline & 22 노래하기를 좋아한다. & 3.98 & 4.36 & 3.94 & 3.81 & 0.41 \\
\hline \multirow{5}{*}{ (3) Social / Conversation skills } & 5 낯선 사람에게 먼저 말을 건다. & 2.44 & 2.45 & 2.31 & 2.52 & 0.06 \\
\hline & 6 상대방과 말을 주고받으며 대화한다. & 4.56 & 3.55 & 5.00 & 4.76 & $4.16^{*}$ \\
\hline & 9 적당한 크기로 말한다. & 4.38 & 4.73 & 4.13 & 4.38 & 0.68 \\
\hline & 11 대화 중에 부적절한 목소리를 낸다. & 4.31 & 3.64 & 4.88 & 4.24 & 2.67 \\
\hline & 17 조용히 하라고 말하면 따른다. & 4.62 & 3.73 & 4.69 & 5.05 & $3.46^{*}$ \\
\hline
\end{tabular}

The items 11 and 20 were reverse scored. ${ }^{*} p<0.05,{ }^{\dagger} p<0.001$. ABEL: Auditory Behavior in Everyday Life

과, 이 다섯 문항에서 유아 연령대가 다른 연령대에 비해 유의 미하게 낮은 점수를 보였다.

본 연구의 대상이 된 청각장애 아동 48 명의 점수를 연령대와 평가영역별로 살펴본 결과를 Figure 1과 Table 3에 제시하였다. 평균 점수는 전체 연령대에서 4.21(SD: 0.87), 유아 연령대(11 명)에서 3.96(SD: 0.87), 초등 연령대(16명)에서 4.36(SD: 0.89), 중등 연령대(21명)에서 4.30(SD: 0.85)이었다. 연령대와 평가영 역별의 평균점수에 대한 상호작용과 주효과를 분석하기 위해 혼합요인 분산분석을 실시한 결과, 연령대와 평가영역 간의 상 호작용은 $[\mathrm{F}(4,90)=0.613, p>0.05]$ 로 유의하지 않았다. 연령 대의 주효과는 $[\mathrm{F}(2,45)=1.442, p>0.05]$ 로 유의하지 않았으나 평가영역의 주효과는 $[\mathrm{F}(2,90)=5.870, p<0.01]$ 로 유의했으며, 사후분석 결과 청각적 인식 영역이 사회적/대화 기술 영역보다

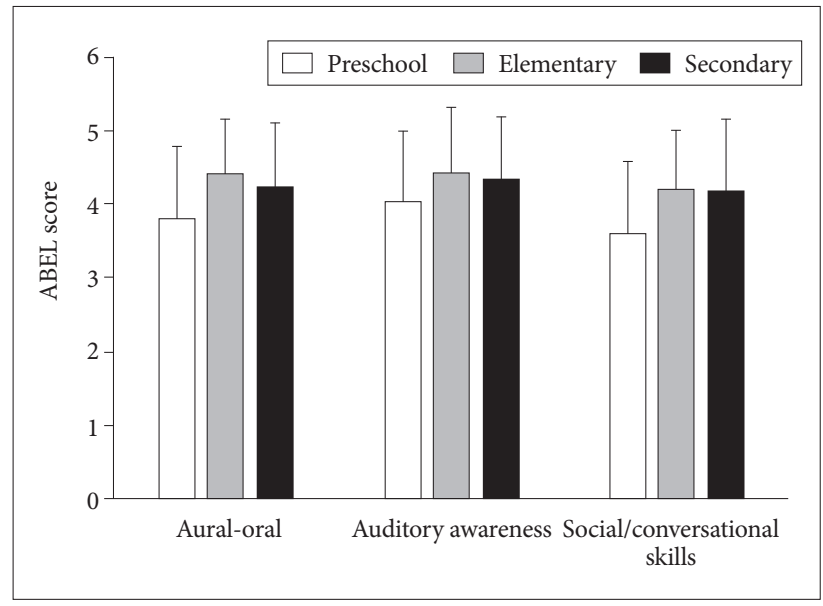

Figure 1. $A B E L$ performance for the age groups. ABEL: Auditory Behavior in Everyday Life. 
Table 3. Statistical analysis of ABEL performance according to age and evaluation area

\begin{tabular}{lcccc}
\hline & Preschool & Elementary & Secondary & F-value* \\
\hline Aural-oral & $3.82 \pm 0.98$ & $4.43 \pm 0.76$ & $4.25 \pm 0.86$ & 1.084 \\
Auditory awareness & $4.07 \pm 0.96$ & $4.45 \pm 0.89$ & $4.37 \pm 0.84$ & 0.907 \\
Social/Conversational skills & $3.62 \pm 0.97$ & $4.20 \pm 0.81$ & $4.19 \pm 0.99$ & 1.306 \\
F-value* & 2.775 & 2.430 & 0.964 & \\
\hline
\end{tabular}

*All F-values are not significant $(p>0.05)$
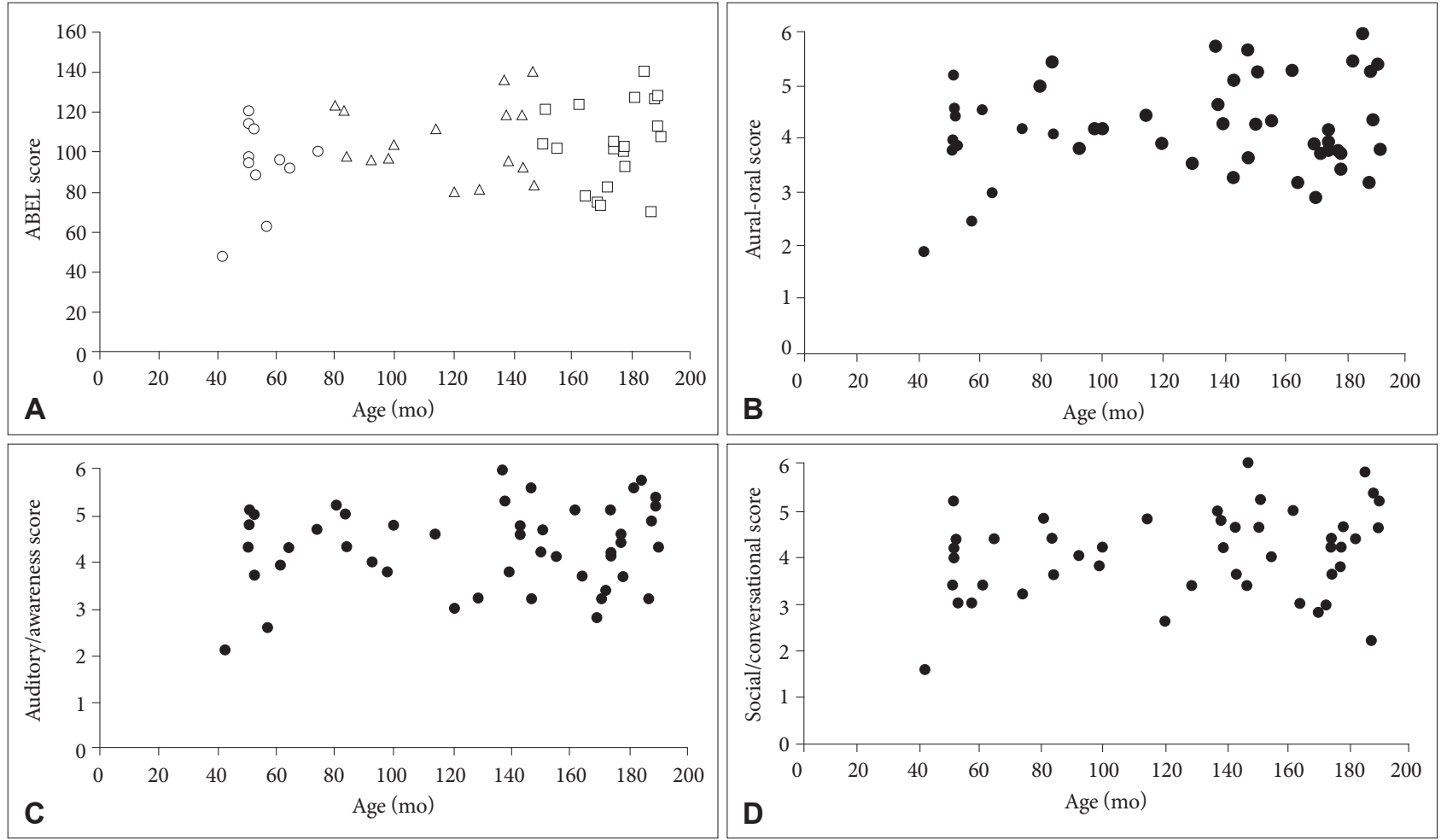

Figure 2. Correlation between chronological age and (A) ABEL total score (o: Preschool, $\triangle$ : Elementary, $\square$ : Secondary). Correlation between chronological age and each area (B: Aural-oral score. C: Auditory awareness score. D: Social/Conversational score). ABEL: Auditory Behavior in Everyday Life.

유의하게 높은 점수를 보였다 $(p<0.01)$. Table 3은 각 평가영역 별 연령대 간 비교를 위하여 독립표본 일원분산분석을, 연령대 별 평가영역 간 비교를 위해 반복측정 일원분산분석을 각각 실 시한 결과를 제시한 것으로, 각 평가영역별, 연령대 간 그리고 각 연령대별 평가영역 간의 유의미한 차이는 없었다 $(p>0.05)$.

\section{생활연령, $\mathrm{Cl}$ 착용기간과 $\mathrm{ABEL}$ 점수 간 상관성 분석}

생활연령과 $\mathrm{ABEL}$ 점수와의 상관성

청각장애 아동의 생활연령과 $\mathrm{ABEL}$ 점수 간의 상관관계를 분석한 결과(Figure 2$)$, 유아 $(\mathrm{r}=0.21, p>0.05)$, 초등 $(\mathrm{r}=0.02$, $p>0.05)$, 중등 $(\mathrm{r}=0.19, p>0.05)$, 전체 아동 $(\mathrm{r}=0.21, p>$ 0.05) 모두 유의미한 관계가 없었다. 청각장애 아동의 생활연령 과 $\mathrm{ABEL}$ 의 세 가지 영역 간의 상관관계를 분석한 결과, 청각구화 $(\mathrm{r}=0.17, p>0.05)$, 청각적 인식 $(\mathrm{r}=0.15, p>0.05)$, 사회
적/대화 기술 $(\mathrm{r}=0.25, p>0.05)$ 모두 유의미한 관계가 없었다.

\section{$\mathrm{Cl}$ 착용기간과 $\mathrm{ABEL}$ 점수 간의 상관성}

청각장애 아동의 $\mathrm{CI}$ 착용기간과 $\mathrm{ABEL}$ 점수 간의 상관관계 를 분석한 결과(Figure 3$)$, 유아 $(\mathrm{r}=0.46, p>0.05)$, 초등 $(\mathrm{r}=$ $0.27, p>0.05)$, 중등 $(\mathrm{r}=0.46, p>0.05)$ 집단 모두 유의미한 관계가 없었으나, 전체 연령대에서 유의미한 상관관계가 있는 것으로 나타났다 $(\mathrm{r}=0.38, p<0.05)$. CI 착용기간과 $\mathrm{ABEL}$ 의 세 가지 영역 간의 상관관계를 분석한 결과, 청각-구화 영역은 상관관계가 없었으나 $(\mathrm{r}=0.30, p>0.05)$, 청각적 인식 $(\mathrm{r}=0.36$, $p<0.05)$ 과 사회적/대화 기술 $(\mathrm{r}=0.43, p<0.01)$ 영역은 유의 한 상관관계가 있는 것으로 나타났다. 

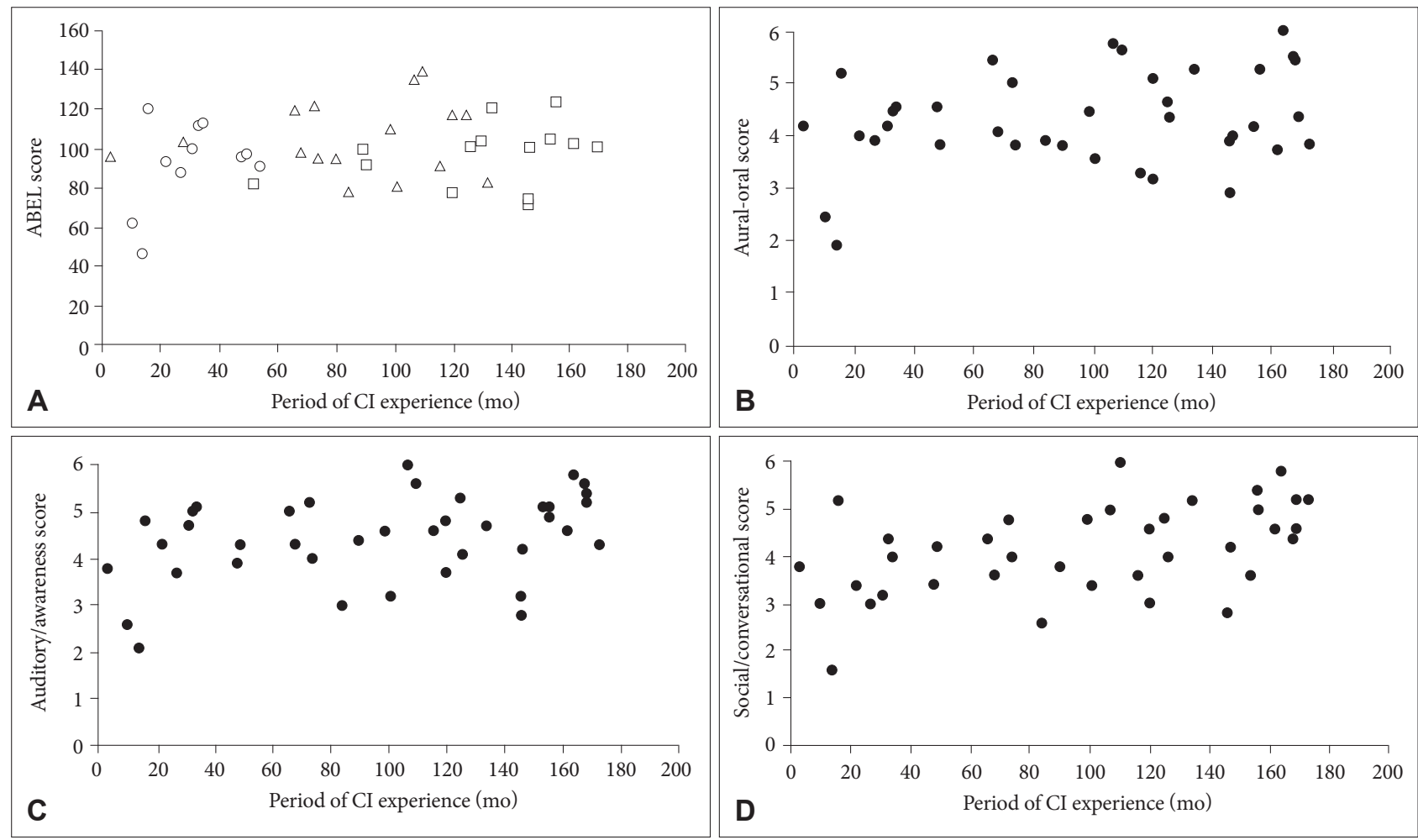

Figure 3. Correlation between period of $\mathrm{Cl}$ experience and (A) ABEL total score (o: Preschool, $\triangle$ : Elementary, $\square$ : Secondary). Correlation between $\mathrm{Cl}$ experience and each area (B: Aural-oral score. C: Auditory awareness score. D: Social/Conversational score). ABEL: Auditory Behavior in Everyday Life.

\section{DISCUSSIONS}

청각장애 아동의 청각행동을 부모가 평가할 수 있도록 고안 된 설문지인 $\mathrm{ABEL}$ 은 높은 신뢰도와 타당도로 영어권 및 타 언어권에서는 임상적으로 널리 사용되고 있다. 본 연구에서는 국내 청각장애 아동을 대상으로 한 $\mathrm{ABEL}$ 설문지의 신뢰도와 타당도를 확인하기 위해서 한국어로 번역한 $\mathrm{ABEL}$ 설문지 검 사를 국내 청각장애 아동의 부모 48명에게 실시하였다. ABEL 설문지의 적용 연령대는 4 14세로 제안되고 있으나(Zanzani et al., 2016), 각 설문지에서 정하는 대상연령 범위를 엄격히 적용 하기보다는 아동의 듣기능력에 따라 적절한 설문지를 사용할 것을 권고하는 의견도 있으며(Bagatto et al., 2011), 국내 중등 교육과정 학제가 만 15 세 기준이므로 본 연구에서는 15 세 아 동까지 포함하였다.

한국어 버전 ABEL 설문지의 신뢰도를 측정하기 위해 크론 바흐 알파값을 확인한 결과 전체 영역에서 0.90 으로 나타나, 영 어 0.94(Purdy et al., 2002), 브라질어 0.93(Souza et al., 2011), 페르시아어 0.82(Zanjani et al., 2016) 등 타 언어권과 비슷한 수준을 유지하는 것으로 나타났다. 한국어 버전 ABEL의 세 가지 영역별로는 청각-구화 영역에서 0.82 로 가장 높게 나타났 고, 다음으로 청각적 인식 영역에서 0.76 , 사회적/대화 기술 영
역에서 0.61 로 가장 낮게 나타났다. 이와 같은 경향은 브라질어 버전(Souza et al., 2011)과 페르시아 버전(Zanjani et al., 2016) 에서도 동일하게 나타났는데, 각 언어권에서 공통적으로 사회 적/대화 기술 영역이 다른 영역들보다 낮게 나타나는 것은 해 당 영역이 아동의 청각능력을 간접적으로 평가하기 때문인 것 으로 볼 수 있다. 그 중 한국어 버전에서 사회적/대화 기술 영 역이 유독 낮게 나타난 것은 한 문항(문항 5 낮선 사람에게 먼 저 말을 건다)이 평균 2.44점으로 전체 영역과 연령대에서 가장 낮은 점수를 받은 것과 관련이 있는데, 해당 문항을 제외했을 때 사회적/대화 기술 영역의 크론바흐 알파값이 기존의 0.61에 서 0.69 로 상승하는 것으로 나타났다. 이는 아동의 사회적 상호 작용 양상에 대한 문화적 인식의 차이가 영향을 미친 결과로 추정된다. 문항 5 는 $\mathrm{ABEL}$ 설문지를 활용할 때 문화권에 따라 결과가 달라질 수 있는 가능성을 시사해주는 한 예로서, 상대 에게 먼저 말을 거는지를 묻거나(1번, 5 번) 상대의 이름을 말하 는지를 묻는(2번, 14 번) 문항들에 포함된다. 아동의 이런 행동 들은 동양 문화권에서 상대에 따라서는 신중하지 못하거나 심 지어는 무례한 행동으로 여겨질 수도 있다. 특히 국내 아동들은 낮선 사람을 경계하도록 교육받는 경향이 있으므로 문항 5(낯 선 사람에게 먼저 말을 건다)와 문항 13(낮선 사람(들)이 반겨주 면 소리내어 답한다)의 경우에도 그 타당도가 문제될 수 있다. 
$\mathrm{ABEL}$ 설문지가 타 설문지들에 비해 유독 짧고 간결한 문항 들로 구성되어 있는 점 또한 타당도에 부정적인 것으로 보인다. 비록 문항의 간결성이 응답자의 부담을 줄이고 시행용이성을 높인 면이 있으나, 그로 인해 맥락의 혼동을 야기하는 측면도 있다. Souza et al.(2011)은 ABEL 설문지를 브라질어로 번역하 는 과정에서의 어려움들을 언급하며 6번(Takes turns in conversations), 11번(Makes inappropriate vocal noises), 24번 (Experiments with newly discovered sounds) 문항들에서 설 문지 응답 과정에 이해상의 문제가 발생했고, 이에 따라 대체어 의 사용과 추가적인 설명이 요구되었음을 보고하였다. 특히 부 모들이 가장 이해하기 어려워했던 것이 문항 16(Will whisper a personal message)이었음을 밝히면서, 해당 문항이 단순히 특정 행위의 유무를 묻는 것인지 아니면 아동의 평소 경향을 묻는 것인지 애매한 점에서 비롯된 것으로 보았다. ABEL의 한 국어 번역의 내용타당도 조사에서도 동일 문항들이 지적되었 는데, 11 번 문항이 평균 3.71점으로 가장 낮은 점수를 받았으며, 다음으로 24번 문항이 4.00점을 받았다. 특히 16번 문항은 애 매성과 문화적 차이로 인한 이해상의 문제가 중첩되면서 가장 많은 지적을 받았으므로 원문의 의도를 해치지 않는 선에서 적 극적으로 의역하였다. 또한 문항 22(Sings)에서도 애매성이 두 드러짐에 따라 '노래한다.로 1 차 번역된 것을 '노래하기를 좋아 한다.로 수정하였다. 설문지 응답 과정에서 부모에게 많은 문의 를 받은 것은 문항 $6,11,24$ 였는데, 문의 내용은 Souza et al. (2011)이 보고한 것과 마찬가지로 해당 문항이 단순히 특정 행 동의 유무를 묻는 것인지 아니면 아동의 평소 경향을 묻는 것 인지 확인하는 것이었다.

역으로 번역 검토과정이나 설문과정에서 제기된 문제는 없었 지만 본 연구의 결과에 의해 향후 재검토가 고려되는 문항도 있었다. 문항 10 (필요하면 도움을 요청한다)은 유아 연령대의 청각-구화 영역에서 5.09점으로 가장 높은 점수를 받았으며, 전 연령대에 걸쳐서도 가장 높은 점수인 것으로 나타났다(Table 3). 도움을 요청하는 의사소통 방식이 구화 이외에 몸짓 등을 통해 서도 이루어질 수 있음을 고려했을 때, 도움을 요청하는 방식 을 구두로 한정하지 않은 결과로 높은 점수가 도출된 것일 수 도 있다. 그러므로 문항 10 번의 내용을 구두 방식으로 한정하 기 위해서 '필요하면 (구두로) 도움을 요청한다.'로 수정하여 사 용하는 것이 적절할 것이다.

국내 청각장애 아동의 $\mathrm{ABEL}$ 을 통한 청각행동을 살펴보았 을 때, 연령대(유아, 초등, 중등) 및 생활연령에 따른 $\mathrm{ABEL}$ 점 수에 유의미한 차이가 없는 것으로 나타나, 생활연령이 청각 발 달을 유효하게 설명해주지 못하는 것으로 나타났다. 그러나 $\mathrm{ABEL}$ 의 세 가지 평가영역에 따라서는 유의한 차이가 있는 것 으로 나타났다. 서로 유의한 차이가 있는 영역은 청각적 인식
영역과 사회적/대화 기술 영역이었는데, 청각적 인식 영역의 경 우, 단순한 청각적 인식 문항들 $(8,15,19,20,23)$ 의 점수가 4점 대 이상이었던 반면, 청각적 인식에 대한 아동의 적극성 등 개 별적 성향이 반영되는 문항들 $(7,16,24)$ 은 2 3점으로 상대적으 로 낮은 점수를 보였다. 사회적/대화 기술 영역에서는 앞서 지 적하였듯 문화적인 요소에 영향을 받은 문항 5 를 제외하면 나 머지 문항에서 모두 4점대 이상으로 나타났다.

그러나 문항별로 살펴보았을 때는 초등 연령대와 중등 연령 대 간에는 유의미한 차이가 나타나지 않았지만, 유아 연령대와 그 이상의 연령대 사이에 유의미한 차이를 보이는 등 연령 발 달에 영향을 받는 문항들이 있는 것으로 나타났다(문항 6,7 , $14,16,17)$. 이는 $\mathrm{ABEL}$ 설문지를 통해 연령에 따른 청각발달 을 설명하는 것은 초등 연령대까지 유효함을 시사한다고 할 수 있다. 그러나 CI 아동의 착용기간과 $\mathrm{ABEL}$ 점수 간의 상관관계 는 각 연령대별로 유의미한 관계가 없었으나, 전체 연령대에서 유의미한 상관관계가 있는 것으로 나타났으며, 특히 청각적 인 식 영역과 사회적/대화 기술 영역에서 유의한 상관성을 보였으 므로 CI 착용기간이 늘어나면서 청각적 인식과 사회적/대화 기 술 측면에서 발달 특성을 보이는 것으로 나타났다. 그러므로 $\mathrm{CI}$ 착용 아동의 경우에는 그 이상의 연령대까지 청각발달이 유 효한 변인인 것으로 나타났으므로 $\mathrm{ABEL}$ 설문지의 사용은 최 소 15 세까지 무방할 것으로 여겨진다.

본 연구에서는 한국어 버전 $\mathrm{ABEL}$ 의 신뢰도 검증이 내적 일 관성 측정에 국한되어 시간 경과에 따른 검사의 신뢰성 등에 대 한 측정이 이루어지지 않은 제한점이 있으므로, 향후 후속 연구 에서 검사-재검사 신뢰도 검증 등 다양한 측면에서의 신뢰도 검증이 이루어질 필요가 있다. 또한 기존 연구들에서는 아동의 연령 증가에 따른 $\mathrm{ABEL}$ 점수의 향상이 관찰되었으나(Purdy et al., 2002; Zanjani et al., 2016), 본 연구에서는 CI 착용기간 과의 유의미한 상관성만이 관찰되었다. 이는 본 연구에서 유아 및 초등 연령대 연구대상자 수가 상대적으로 적어 구체적인 경 향을 살펴보기에 제한이 있었던 것으로 볼 수 있다. 그러므로 아동의 일상생활 청각행동의 발달 특성을 면밀히 살피기 위해 서는 보다 충분한 대상자 수가 확보된 후속 연구가 필요함을 시사한다.

본 연구에서 한국어 버전 $\mathrm{ABEL}$ 의 신뢰도는 우수한 것으로 나타났으나, 지나치게 간결한 문항이 응답자에게 혼동을 야기 하는 점과 영어권에서 개발된 $\mathrm{ABEL}$ 설문지의 몇 문항들이 동 양 문화권에서는 적절하지 않은 점 등 타당도 측면에서는 신중 하게 접근해야 할 필요가 있는 것으로 나타났다. 이러한 문제 들에도 불구하고 $\mathrm{ABEL}$ 설문지는 짧고 간결한 문항과 적정 수 준의 문항 수로 인한 높은 시행용이성, 영어권 등에서의 높은 신뢰도와 타당도, 그리고 특히 아동 대상의 설문지 중에서 유 
일하게 아동의 사회적 상호작용 및 대화 기술에 대한 정보를 제공해 주는 고유한 장점을 갖고 있으므로, 결과 해석에 주의 를 기울인다면 국내 환경에서 $\mathrm{ABEL}$ 설문지를 사용하는 것은 의미있는 일일 것이다. 또한 향후 국내에서 청각장애 아동을 대 상으로 하는 설문지가 개발될 경우에 유용한 시사점들을 제공 해줄 수 있을 것으로 기대한다.

\section{중심 단어 : 일상생활 청각행동·설문지·청각장애 아동.} 신뢰도.

\section{REFERENCES}

American Speech-Language-Hearing Association (ASHA). (2001). Knowledge and skills required for the practice of audiologic/aural rehabilitation. Retrieved from http://www.asha.org/policy/KS2001-00216/.

Anderson, K. L. \& Matkin, N. D. (1991). Relationship of degree of longterm hearing loss to psychosocial impact and educational needs. Educational Audiology Association Newsletter, 8, 17-18.

Bagatto, M. P., Moodie, S. T., Malandrino, A. C., Richert, F. M., Clench, D. A., \& Scollie, S. D. (2011). The University of Western Ontario pediatric audiological monitoring protocol (UWO PedAMP). Trends in Amplification, 15(1), 57-76.

Choi, J., Yoo, J., Jo, J., Han, S., Kwak, J., \& Jang, H. (2015). A systematic analysis on questionnaires for children with hearing loss. Audiology, 11(4), 331-347.

Geal-Dor, M., Jbarah, R., Adler, M., Yehezkely, M. K., \& Adelman, C. (2014). Auditory Behavior in Everyday Life (ABEL) questionnaire in Hebrew and in Arabic and its association with clinical tests in cochlear-implanted children. Journal of Basic and Clinical Physiology and Pharmacology, 25(3), 301-306.
Gfeller, K. E. \& Schum, R. (1994). Requisites for conversation: Engendering world knowledge. In N. Tye-Murray (Ed). Let's Converse: A "How-To" Guide to Develop and Expand Conversational Skills of Children and Teenagers who are Hearing Impaired (pp. 177-212). Washington, DC: Alexander Graham Bell Association.

Herrera, M. J., Mena, P., Cardemil, F., Fuentes, E., Rahal, M., Sanhueza, D., et al. (2015). Adaptación transcultural al español de los instrumentos de tamizaje auditivo para escolares TEAP y ABEL. Revista de Otorrinolaringología y Cirugía de Cabeza y Cuello, 75(2), 89-95.

Paul, P. V. \& Jackson, D. W. (1993). Toward a Psychology of Deafness: Theoretical and Empirical Perspectives. Boston, MA: Allyn \& Bacon.

Purdy, S. C., Farrington, D. R., Moran, C. A., Chard, L. L., \& Hodgson, S. A. (2002). A parental questionnaire to evaluate children's Auditory Behavior in Everyday Life (ABEL). American Journal of Audiology, 11(2), 72-82.

Schloss, P. J. \& Smith, M. A. (1990). Teaching Social-Skills to Hearing-Impaired Students. Washington, DC: Alexander Graham Bell Association.

Schum, R. L. (1991). Communication and social growth: A developmental model of social behavior in deaf children. Ear and Hearing, 12(5), 320 327.

Souza, M. R. F. D. \& Iorio, M. C. M. (2014). Questionnaire ABEL-Auditory Behavior in Everyday Life: A study of reliability-internal consistency of the brazilian version and reproducibility for test-retest. Revista $C E$ FAC, 16(6), 1763-1774.

Souza, M. R. F. D., Osborn, E., Gil, D., \& Iório, M. C. M. (2011). Translation and adaptation of the ABEL: Auditory behavior in everyday life questionnaire into Brazilian portuguese. Jornal da Sociedade Brasileira de Fonoaudiologia, 23(4), 368-375.

Zanjani, M. O., Purdy, S. C., Vahab, M., Rasouli, J., Vasfinia, M., \& Lotf, Z. (2016). Translation and adaptation of the auditory behavior in everyday Life (ABEL) questionnaire into persian: A pilot study. Journal of Rehabilitation Sciences and Research, 2(3), 63-67. 